\title{
Job descriptions for Regional Representatives and Specialty Tutors
}

The following job descriptions were approved by the Court of Electors at its meeting on 19 October 1998.

\section{Regional Representatives}

Regional Representatives are internal College appointments made to assist Regional Advisers and the Chairmen of Divisions, Faculties and Sections on a variety of salient specialist issues. There are no Regional Representatives in Scotland due to different systems in operation, and the existence of the National Panel of Specialists.

\section{Method of appointment}

Regional Representatives are nominated by the Chairman of the relevant Faculty in consultation with their Executive Committee and the Chairman of the relevant Division. The joint nomination shall be forwarded to the Court of Electors which makes the final decision to appoint. Regional Representatives may hold other offices, such as membership of the Executive Committee of a Faculty or Division. They may also be Specialty Tutors.

\section{Term of office}

Five years.

\section{Duties}

- To provide relevant specialist advice to College Regional Advisers in relation to job descriptions for consultants, specialist registrars and associate specialists. Regional Representatives should be consulted about job descriptions by the Regional Adviser. but they will not be expected to give direct advice to employing authorities.

- To offer advice on other salient aspects of services and implementation of College policy.

- To alert/consult the Chairmen of the relevant Division, Faculty or Section on any local issues of importance in relation to services for the speciality.
- To provide the Division, Faculty and Specialist Advisory Committee of the Higher Specialist Training Committee (HSTC) with regular information concerning workforce issues to try to ensure that there is an appropriate number of trainees to meet the future need for consultants.

- To assist Deputy Regional Advisers and Faculty/Section Executive Committees with the collection of Census data.

- To offer advice to Chairmen of the relevant Division, Faculty or Section on nominations for the College Fellowship.

- To offer advice to Chairmen of the relevant Division, Faculty or Section on nominations for Distinction Awards.

- Regional Representatives may be asked to serve on Advisory Appointments Committees for consultants, specialist registrars and associate specialists, except in Scotland.

- To liaise with their local Specialty Tutor on manpower issues.

\section{Specialty Tutors}

The Specialty Tutor practises in one or more of the fields of child and adolescent psychiatry, psychotherapy, forensic psychiatry, psychiatry of learning disability, psychiatry of old age and substance misuse.

This individual is regarded as the tutor with responsibility for providing advice on or the organisation of training in that speciality for the Region. It follows, therefore, that there would normally be one tutor for each speciality in any one region. Such a person may often be the Regional Representative in that speciality (see separate job description).

\section{Method of appointment}

Specialty Tutors are nominated by their local Training Committee, and then must be approved by the Court of Electors.

\section{Term of office}

Five years. 


\section{Duties}

- To provide advice on psychiatric training in a specific speciality for the Region.

- To provide advice on the organisation of psychiatric training in a specific speciality for the Region.

- To promote training in their specific speciality at all levels.

- To have an in-depth knowledge of the Scheme and training opportunities available thereon.

- To have a knowledge of the College curriculum and knowledge of and input into local MRCPsych courses.
- To advise specialist registrars on training and educational requirements for both single Certificate of Completion of Specialist Training (CCST) and dual CCST.

- To encourage specialist registrars to undertake research and to participate in regional academic and clinical meetings.

- To have a role in counselling and supporting trainees experiencing training difficulties.

- To sit on appropriate training/education committees.

- To disseminate information from the College concerning conferences, courses and events.

\section{New in the College Seminars series

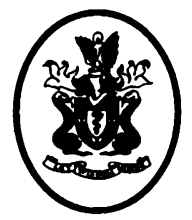 \\ Seminars in \\ Old Age Psychiatry}

Edited by Rob Butler and Brice Pitt

This book offers a concise and up-to-date text on the mental health of older people. A stepby-step approach to assessment is followed by chapters covering the important psychological conditions of older age. There are practical guidelines on clinical management, and sections covering topics such as law and research. The book ends with a collection of vignettes which allow the reader to test their knowledge.

With the growing importance of old age psychiatry, this book will be invaluable to trainee and qualified psychiatrists, as well as other doctors, medical students and health care professionals who work with older people.

November 1998, 356pp, Paperback, ISBN 190124221 8, £17.50

Available from Book Sales, Royal College of Psychiatrists, 17 Belgrave Square, London SW1X 8PG. Tel: +44 (0)1712352351, ext. 146, Fax: +44 (0) 1712451231

The latest information on College publications is on the INTERNET at: $h$ ttp://www.ncpsych.ac.uk 